\title{
Designing a Trading Card Game as Educational Reward System to Improve Students' Learning Motivations
}

\author{
Peayton Chen ${ }^{1}$, Rita Kuo ${ }^{2}$, Maiga Chang ${ }^{3}$, and Jia-Sheng $\mathrm{Heh}^{1}$ \\ ${ }^{1}$ Dept. of Information and Computer Engineering, Chung-Yuan Christian Univ., Taiwan \\ peayton@hotmail.com, jsheh@ice.cycu.edu.tw \\ ${ }^{2}$ Dept. Of Digital Design, Mingdao Univ., Taiwan \\ rita@mdu.edu.tw \\ ${ }^{3}$ School of Computing and Information Systems, Athabasca University, Canada \\ maiga@ms2. hinet. net
}

Reward is the simplest way to motivate students in education. It can encourage students to learn and get immediate achievement. Moreover, it is also has potential to construct students' intrinsic motivation. However, traditional symbolic rewards like stars or stickers are often less valuable because it cannot be used by the students after the class; thus cannot keep motivating students.

This research designed cards of a self-developed computerized trading card game (TCG) as educational rewards in order to inspire students learning. The teacher can give the student cards if the student did well in either his/her homework, quiz, or exam. Also, the teacher can give the student different level cards according to his/her answers to the question the teacher asked; or according to the student's learning attitude and performance. Teachers can pre-define the relation between the learning and the reward, the system then can give appropriate cards to students automatically according to the relation. Furthermore, because of the cards and the computerized TCG is independent from the courses, teaches can map the same card to verity courses to let students get cards from any courses.

For this purpose, this research analyzed three famous TCGs and implemented a prototype computerized TCG and educational reward system to increase student's learning motivation. Students can collect cards in class and use it for play or even show-off after class, which can really encourage students to learn. These cards in the computerized TCG not only can increase the usability of rewards, but also can stimulate students' learning motivations because of more they've learned or better they've performed, more and better cards they can get and use to play the game and defeat the fellows easier. Because the computerized TCG is real game, it is fun and will not make students feel they are still "learning". Through the TCG, the rewards can hold students' interest for longer.

Keywords: Trading Card Game, Reward, Learning motivation, Competition, Game. 